\title{
Pelatihan dan Pemanfaatan Aplikasi Dewan Masjid Indonesia (DMI) Berbasis Web Untuk Pengelolaan Produk dan Kegiatan Masjid Sebagai Dukungan Layanan Masyarakat Kota Semarang
}

\section{Training and Utilization of Web-Based Application of the Indonesian Mosque Council (DMI) for the Management of Mosque Products and Activities as a Support for Semarang City Community Services}

\author{
Nurul Anisa Sri Winarsih ${ }^{1}$, Muhammad Syaifur Rohman ${ }^{2}$, Galuh Wilujeng Saraswati ${ }^{3}$ \\ ${ }^{1,2,3}$ Fakultas Ilmu Komputer, Universitas Dian Nuswantoro \\ E-mail: ${ }^{1}$ nurulanisasw@dsn.dinus.ac.id, ${ }^{2}$ syaifur@dsn.dinus.ac.id, ${ }^{3}$ galuhwilujengs@ \\ dsn.dinus.ac.id
}

\begin{abstract}
Abstrak
Suatu kota wajib memiliki aset potensial untuk mendukung pengembangan wilayahnya. Dan masjid merupakan salah satu fasilitas umum yang termaksud dalam bagian dari aset potensial suatu kota. Untuk mengoptimalkan fungsi dan potensi masjid, perlu dilakukan identifikasi untuk meningkatkan kapasitas masjid melalui koordinasi pengurus dalam menjalankan fungsi masingmasing. Oleh karena itu, diperlukan sebuah platform untuk menampung data kegiatan masjid seluruh kota Semarang, sehingga data-data Masjid se-kota Semarang dapat dikelola dengan baik melalui sebuah platform web. Pembuatan aplikasi ini digunakan Dewan Masjid Indonesia (DMI) sebagai media pengelolaan informasi tentang kegiatan masjid, lokasi masjid hingga infomasi produk-produk milik jamaah. Pendataan kegiatan dan potensi ekonomi masyarakat sekitar masjid dapat dilakukan menggunakan bantuan teknologi website yang dilengkapi Sistem Infromasi Geografis (SIG). Seluruh data aset potensial masjid akan tersimpan dalam database web dan ditampilkan melalui aplikasi DMI kota Semarang berbasis android. Dua komponen ini akan saling berintegrasi untuk memenuhi tujuannya.
\end{abstract}

Kata kunci: Web, Sistem Infromasi Geografis, DMI

\section{Abstract}

A city must have potential assets to support the development of its territory. And the mosque is one of the public facilities referred to in part of the potential assets of a city. To optimize the function and potential of the mosque, identification needs to be done to increase the capacity of the mosque through coordinating the management in carrying out their respective functions. Therefore, a platform is needed to collect data on mosque activities throughout the city of Semarang, so that mosque data throughout the city of Semarang can be managed properly through a web platform. The making of this application is used by the Indonesian Mosque Council (DMI) as a media for managing information about mosque activities, mosque locations, and information on pilgrims' products. The data collection of activities and the economic potential of the community around the mosque can be done using the help of website technology that is equipped with a Geographic Information System (GIS). All potential mosque asset data will be stored in a web database and displayed through the Semarang-based android city DMI application. These two components will integrate with one another to meet its objectives

Keywords: Web, Sistem Informasi Geografis, DMI 


\section{PENDAHULUAN}

Suatu kota wajib memiliki aset potensial untuk mendukung pengembangan wilayahnya. Aset potensial ini meliputi infrastruktur, fasilitas, orang, komunitas organisasi, dan bea cukai yang dapat mempengaruhi aspek sosial, ekonomi dan budaya [1]. Masjid merupakan salah satu fasilitas umum yang termaksud dalam bagian dari aset potensial suatu kota. Masjid sebagai asset potensial ini tergolong sangat penting bagi suatu kota mengingat penenduk di Indonesia khususnya kota Semarang mayoritas memeluk agama Islam.

Pada masa Nabi, masjid merupakan lambang dari sentral kekuatan masyarakat Islam yang digunakan untuk berbagai kegiatan [2]. Pada zaman sekarang, masjid adalah tempat ibadah bagi umat islam untuk memenuhi kewajiban melaksanakan ibadah shalat lima waktu kepada Allah SWT [3]. Selain itu, masjid sekarang ini di gunakan oleh beberapa komunitas dan organisasi untuk kegiatan sosial kemasyarakatan, peningkatan pendidikan baca tulis Al-Quran dan pembinaan Sumber Daya Manusia (SDM) melalui kajian keagaaman serta pembinaan ekonomi.

Untuk mengoptimalkan fungsi dan potensi tersebut, perlu dilakukan identifikasi untuk meningkatkan kapasitas masjid melalui koordinasi pengurus dalam menjalankan fungsi masingmasing. Oleh karena itu, diperlukan sebuah platform untuk menampung data kegiatan masjid seluruh kota Semarang, sehingga data-data Masjid se-kota Semarang dapat dikelola dengan baik melalui sebuah platform website. Beribadah merupakan kebutuhan dasar setiap umat sehingga salah satu fasilitas umum yang diperlukan oleh masyarakat di Indonesia adalah tempat ibadah [4]. Kota Semarang merupakan ibu Kota Jawa Tengah yang mempunyai 1.162 masjid yang tersebar di seluruh penjuru kota.

Banyaknya jumlah masjid di Kota Semarang ini membuat Pusat Dewan Masjid Indonesia Kota Semarang kesulitan dalam mengelola seluruh fungsi dan kegiatan. Beberapa kendala yang dialami diantaranya kurangnya pengetahuan (pengurus) dalam pengelolaan fungsi masjid khususnya pengelolaan kegiatan sosial kemasyarakatan dan pembinaan ekonomi, melemahnya kegiatan pertemuan rutin jamaahan masjid, dan pembinaan Sumber Daya Manusia Masyarakat sekitar melalui kegiatan kajian islami.

Berdasarkan latar belakang masalah tersebut perlunya sebuah platform yang digunakan sebagai wadah untuk mengidentifikasi, menganalaisis, mengolah dan mengkontrol seluruh fungsi dan kegiatan masjid sehingga keberadaan masjid menjadi sangat potensial untuk mensejakterakaan masyarakat sekitar. Platform yang akan di bangun berbasis framework website yang nantinya akan berfungsi sebagai wadah untuk mengoptimalkan seluruh fungsi dan kegiatan masjid di seluruh Kota Semarang. Dewan Masjid Indonesia (DMI) adalah organisasi tingkat nasional dengan tujuan untuk mewujudkan fungsi masjid sebagai pusat ibadah, pengembangan masyarakat dan persatuan umat. DMI mempunyai beberapa cabang kepengurusan yang tersebar disetiap daerah. DMI pusat juga sudah tersedia dalam bentuk Web Application dan Mobile Application. Selain ketersediaan informasi di berbagai Application, DMI juga rutin melakukan kerjasama, pelatihan dan juga workshop. Namun setelah beberapa review ada beberapa kekurangan yang perlu diperbaiki seperti beberapa menu yang tidak bisa berjalan didalam Mobile Application dan kurang adanya pengembangan masrayakat didalamnya terutama di bidang pemberdayaan ekonomi. Ketersediaan Mobile Application untuk DMI di tiap daerah seperti di kota Semarang juga masih diperlukan untuk mengenalkan DMI lebih dekat lagi dengan masyarakat Indonesia yang mayoritasnya Muslim (pemeluk agama Islam). Dapat diketahui secara umum masjid kota Semarang memiliki kepengurusan yang lengkap dan lebih fokus pada kegiatan peribadatan sedangkan potensi yang lain seperti pembinaan Sumber Daya Manusia dan ekonomi kurang dikembangkan.

Untuk mengoptimalkan fungsi masjid, khususnya untuk meningkatkan pendapatan rumah tangga dan sumber daya manusia masyarakat sekitar masjid perlu dilakukan pendataan dan identifikasi potensi masjid tersebut. Potensi pemberdayaan ekonomi masyarakat berbasis masjid sangat diperlukan sebagai penggerak menjadi ekonomi produktif dalam rangka peningkatan perekonomian masyarakat menjadi lebih baik. 
Pendataan kegiatan dan potensi ekonomi masyarakat sekitar masjid dapat di lakukan menggunakan bantuan teknologi website yang dilengkapi Sistem Infromasi Geografis (SIG). Seluruh data asset potensial smasjid akan tersimpan dalam database web dan ditampilkan melaui aplikasi DMI kota Semarang berbasis android. Dua komponen ini akan saling berintegrasi untuk memenuhi tujuannya.

\section{METODE PELAKSANAAN}

Pelaksanaan kegiatan Pelatihan dan Pemanfaatan Aplikasi Dewan Masjid Indonesia (DMI) Berbasis Web ini memiliki empat tahapan antara lain: Pengumpulan Data, Persiapan Teknis, Pelaksanaan dan Evaluasi

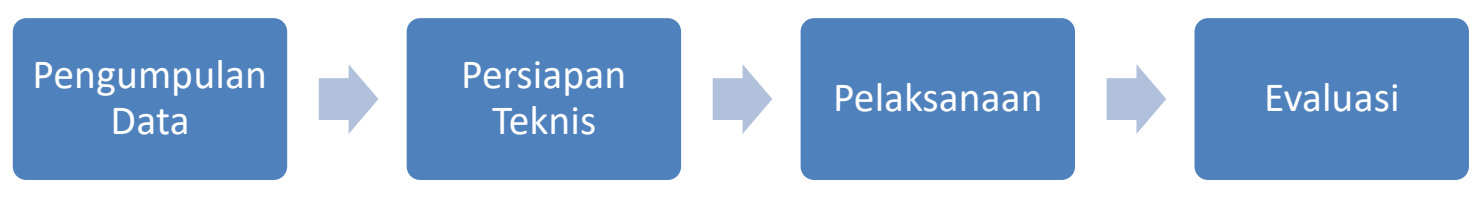

Gambar 1. Tahapan Kegiatan Pengabdian Masyarakat

\subsection{Pengumpulan Data}

Pada tahapan ini merupakan awal dari pelaksanaan pengabdian, berupa koordinasi dengan Mitra yaitu Pengurus Daerah Dewan Masjid Indoensia (DMI) Kota Semarang yang terdiri dari ketua pengurus harian dan Sekertasris II. Koordinasi ini memiliki beberapa tujuan diantaranya: untuk menentukan requirement/ kebutuhan yang diinginkan unuk membangun aplikasi Dewan Masjid Indoensia Kota Semarang berbasis web, menentukan teknis pelaksanaan pengabdian dan mementukan jumlah peserta pelatihan dalam hal ini adalah seluruh takmir masjid di Kota Semarang dan para pengurus inti DMI Kota Semarang.

\subsection{Persiapan Teknis}

Persiapan teknis ini terdiri dari persiapan pembuatan aplikasi memalui pembagian tugas anggota tim perngabdian masyarakat. Pada tahap perancangan pengmbangunan aplikasi tim memilih metode waterfall. Metodologi ini dilakukan secara berurutan dari tahap awal sampai tahapan tersebut selesai dalam mengembangkan sistem tersebut [5]. Langkah-langkah pengembangan website DMI sebagai berikut:

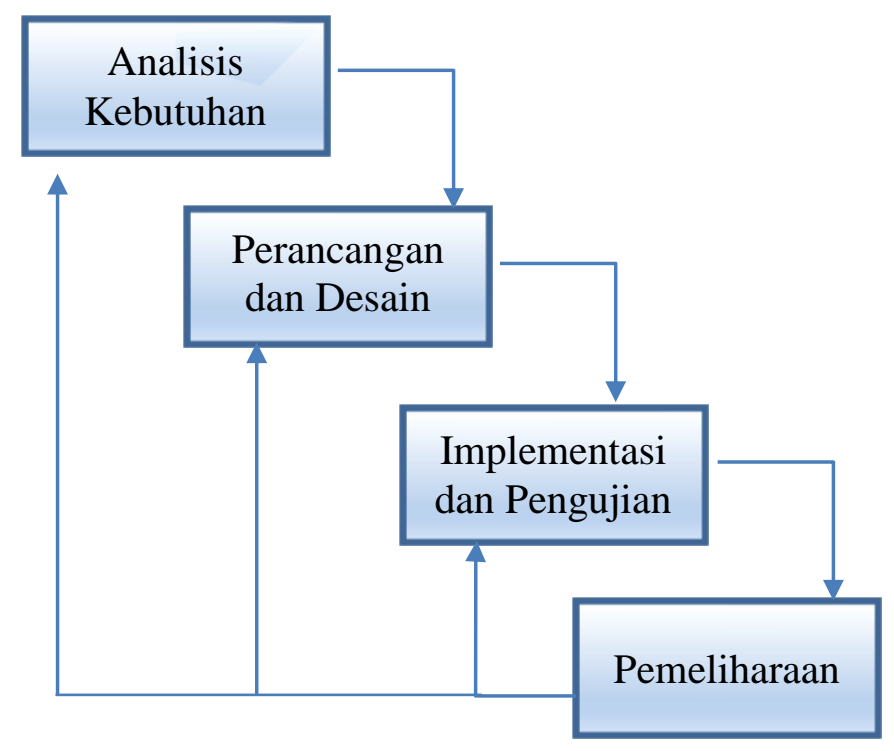


Gambar 2. Langkah-langkah pengembangan website

1. Analisa Kebutuhan.

Didalam tahapan ini hasil konsultasi dengan mitra didefinisikan secara rinci meliputi seluruh layanan yang diberikan oleh website DMI, tujuan dan kendala selama pengembangan webiste

2. Perancangan dan Desain Sistem

Tahap perancangan sistem ini digunakan untuk merancang arsitektur sistem website DMI dari sisi perangkat keras maupun perangkat lunak. Mengingat website DMI ini akan mengelola data seluruh masjid di Kota Semarang sehingga diperlukan perancangan database yang handal dalam menampung seluruh data.

3. Implementasi dan Pengujian

Seluruh kegiatan perancangan yang sudah ditetapkan ditahapan sebelumnya, direalisasikan sebagai serangkaian program. Pengujian merupakan serangkaian aktivitas untuk menguji setiap unit fungsi dalam website DMI.

4. Pemeliharaan

Setelah sistem telah melali uji tingkat fungsionalnya, hasil selama pengujian inilah yang akan kita lakukan selama pemeliharaan. Pada tahap ini melibatkan pembetulan kesalahan, pembaruan implementasi program, dan meningkatkn layanan website sebagai kebutuhan baru

\subsection{Pelaksanaan Kegiatan}

Dalam tahap ini, tim membuat susunan acara pelaksanaan kegiatan pengabdian yang terdiri dari sambutan, pelatihan, dokumentasi kegiatan dan penutup. Pada sesi pelatihan, tim akan menjadi asisten bagi semua peserta pelatihan untuk membantu peserta yang kesulitan dalam pengoperasian website DMI. Pada sesi penutupan peserta diminta untuk memberikan masukan kepada tim untuk meningkatkan hasil aplikasi yang telah dibuat agar sesuai dengan keadaan user.

\subsection{Evaluasi}

Pada tahapan evaluasi ini dilakukan penyusunan laporan pertanggungjawaban kegiatan dan evaluasi kegiatan pelatihan serta diakhiri dengan pembubaraan tim pengabdian ini.

\section{HASIL DAN PEMBAHASAN}

Kegiatan Pengabdian Kepada Masyarakat ini di selanggarakan atas kerjasama Tim Pengabdian Universitas Dian Nuswantoro (UDINUS) dengan Dewan Masjid Indonesia Kota Semarang. Kegiatan pengabdian ini dilaksanakan pada tanggal 29 Maret 2019 di Gedung Balai Kota Semarang yang beralamatkan di Jl. Pemuda No.148, Sekayu, Kec Semarang Tengah, Kota Searang Jawa Tengah. Aplikasi berbasis web DMI Kota Semarang ini memiliki fungsi dan sistem operasi dasar yang akan disajikan pada tabel 1.

Tabel 1 Fungsi Sistem dan Operasi Dasar Website DMI

\begin{tabular}{|c|c|c|}
\hline ID & Fungsi Sistem & Operasi Dasar \\
\hline FS-01 & Pengelolaan Data & $\begin{array}{l}\text { Menambah, mengubah, } \\
\text { menghapus data Admin }\end{array}$ \\
\hline FS-02 & $\begin{array}{l}\text { Melakukan Pengelolaan Gambar } \\
\text { Slider }\end{array}$ & $\begin{array}{l}\text { Menambah, mengubah, } \\
\text { menghapus Gambar Slider }\end{array}$ \\
\hline FS-03 & $\begin{array}{l}\text { Melakukan Pengelolaan Kegiatan } \\
\text { DMI }\end{array}$ & $\begin{array}{l}\text { Menambah, mengubah, } \\
\text { menghapus Kegiatan DMI }\end{array}$ \\
\hline FS-04 & $\begin{array}{l}\text { Melakukan } \\
\text { Masjid }\end{array}$ & $\begin{array}{l}\text { Menambah, mengubah, } \\
\text { menghapus data Masjid }\end{array}$ \\
\hline
\end{tabular}




\begin{tabular}{|l|lll|lr|}
\hline FS-05 & $\begin{array}{l}\text { Melakukan Pengelolaan Kegiatan } \\
\text { di Masjid }\end{array}$ & $\begin{array}{l}\text { Menambah, mengubah, dan } \\
\text { menghapus Kegiatan di Masjid }\end{array}$ \\
\hline FS-06 & $\begin{array}{l}\text { Melakukan } \\
\text { Jamaah }\end{array}$ & Pengelolaan Produk & $\begin{array}{l}\text { Menambah, mengubah, dan } \\
\text { menghapus Produk Jamaah }\end{array}$ \\
\hline FS-07 & $\begin{array}{l}\text { Melakukan } \\
\text { Sholat Pengelolaan Jadwal }\end{array}$ & $\begin{array}{l}\text { Menambah, mengubah, dan } \\
\text { menghapus Jadwal Sholat }\end{array}$ \\
\hline FS-08 & $\begin{array}{l}\text { Melakukan } \\
\text { Khutbah }\end{array}$ & Pengelolaan Materi & $\begin{array}{l}\text { Menambah, mengubah, dan } \\
\text { menghapus Materi Khutbah }\end{array}$ \\
\hline FS-09 & $\begin{array}{l}\text { Melakukan } \\
\text { Mubaligh }\end{array}$ & Pengelolaan C Data & $\begin{array}{l}\text { Menambah, mengubah, dan } \\
\text { menghapus data Mubaligh }\end{array}$ \\
\hline
\end{tabular}

Pada aplikasi berbasis web DMI terdapat dua peran, yaitu super admin dan admin. Semua fungsi di atas dapat dilakukan oleh super admin, sedangkan admin juga dapat melakukan semua fungsi kecuali menambah, mengubah, dan menghapus data admin (FS-01). Perbedaan fungsi tersebut dapat dilihat pada gambar 3. Super admin dan admin merupakan pengurus DMI, developer, maupun semua orang yang sudah diizinkan untuk memiliki akses.

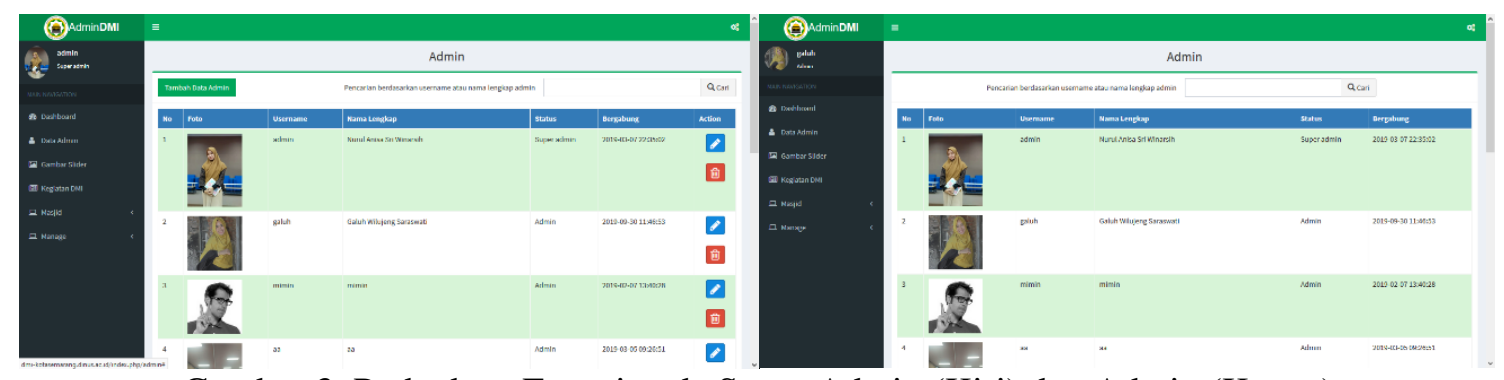

Gambar 3. Perbedaan Fungsi pada Super Admin (Kiri) dan Admin (Kanan)

Kegiatan pengabdian masyarakat dimulai dengan sambutan dari Ketua Pengurus Daerah DMI Kota Semarang yaitu Ir. H. Achmad Fuad. Kegiatan pertama adalah penyampaian materi tentang Penguatan Kelembagaan Ta'mir Masjid. Dilanjutkan dengan sambutan dan perkenalan dari Tim Pengabdian Masyarakat sekaligus menyampaikan materi aplikasi DMI berbasis mobile maupun web.

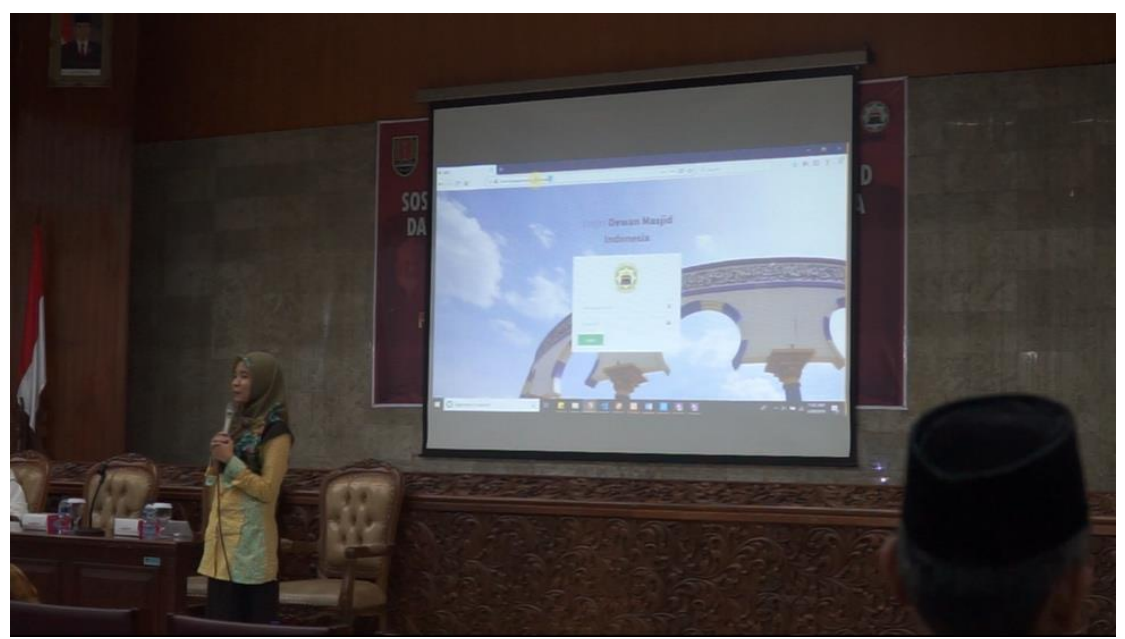

Gambar 4. Penyampaian Materi Aplikasi DMI Berbasis Web

Penyampaian materi website DMI meliputi pelatihan dan pemanfaatan aplikasi untuk mengelola data admin, gambar slider, kegiatan DMI, data masjid, kegiatan di masjid, produk 
jamaah, jadwal sholat, materi khutbah, maupun data mubaligh. Beberapa fungsi dapat dilihat pada gambar 4. Data masjid terdapat 1.170 record, data tersebut bersumber dari data Kementrian Agama melalui website http://simas.kemenag.go.id. Namun, data tersebut harus dilengkapi dengan gambar dan titik koordinat yang akan dilakukan oleh super admin dan admin pada website DMI.
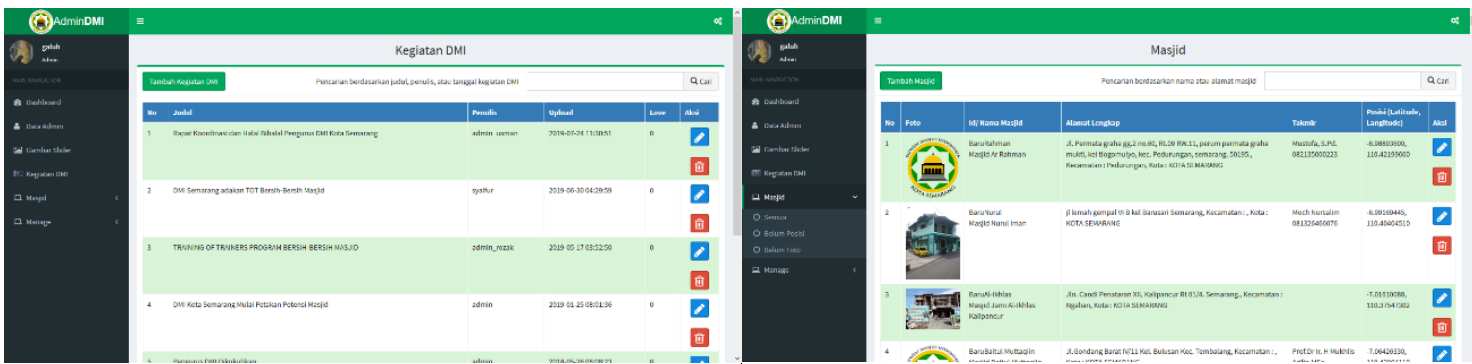

Gambar 4. Fungsi Pengelolaan Kegiatan DMI (kanan) dan Masjid (Kiri)

Khusus untuk Kegiatan Masjid dan Produk Jamaah, data dapat ditambahkan baik melalui website maupun aplikasi android. Pada aplikasi android, siapa saja dapat memasukkan data, data tersebut secara otomatis berstatus draft. Selanjutnya baik super admin dan admin mengaktifkan status publish agar data tersebut dapat ditampilkan ke aplikasi mobile. Visualisasi fungsi terdapat pada gambar 5 dan 6. Tak hanya itu, semua data yang telah dikelola di website DMI akan dapat dilihat pada aplikasi DMI berbasis mobile.
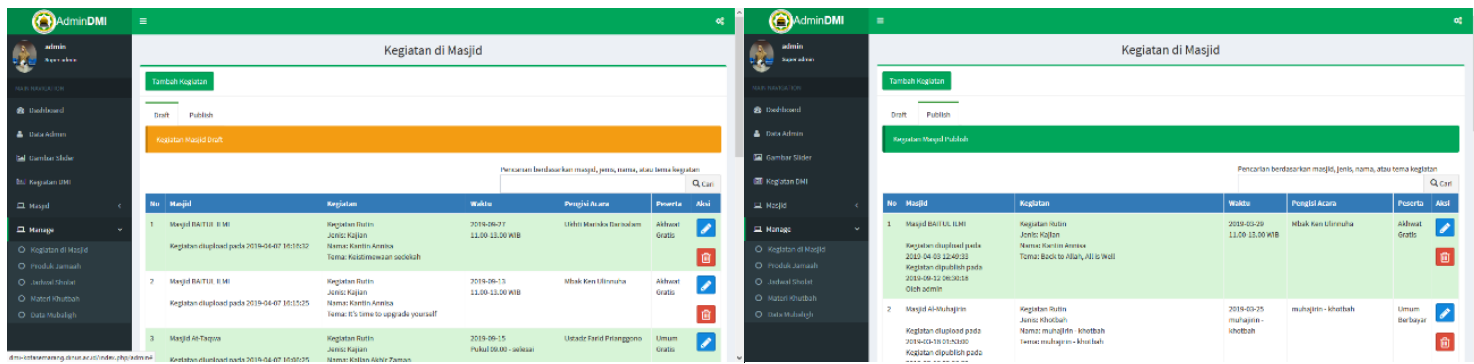

Gambar 5. Kegiatan Masjid Draft (kanan) dan Publish (Kiri)
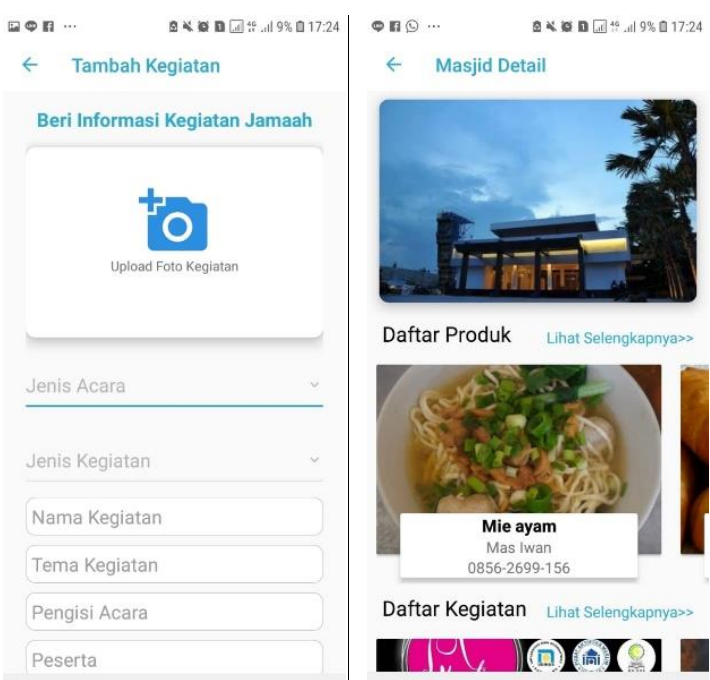

Gambar 6. Mobile Application DMI Upload Kegiatan (Kiri) dan Daftar Produk Kegiatan (Kanan) 


\section{SARAN}

Pengabdian masyarakat ini diselenggarakan di aula tempat berkumpul biasa, karena asumsinya tidak semua orang mendapatakan akses untuk mengelola data pada website DMI. Pada kesempatan mendatang, para peserta pengabdian masyarakat perlu melakukan sosialisasi langsung menggunakan komputer. Sehingga peserta yang berhak mendapatkan akses dapat mencoba secara langsung website DMI pada layar yang besar dan nyaman.

\section{UCAPAN TERIMA KASH}

Termakasih kami ucapkan kepada Lembaga Universitas Dain Nuswantoro yang telah memberikan fasilitas dan dukungan yang diberikan kepada kami dan PD DMI Kota Semarang, sehingga kegiatan pengabdian ini dapat berjalan dengan lancar.

\section{DAFTAR PUSTAKA}

[1] S. A. and R. F. R. M A Muchtar, M F Syahputra, N Syahputra1, "Augmented Reality for Searching Potential Assets in Medan using GPS based Tracking Augmented Reality for Searching Potential Assets in Medan using GPS based Tracking," 2017.

[2] R. Erziaty, "AL-IQTISHADIYAH Jurnal Ekonomi Syariah dan Hukum Ekonomi Syariah," J. Ekon. Syariah dan Huk. Ekon. Syariah Pemberdaya., vol. II, pp. 82-98, 2015.

[3] D. Abdullah and U. Malikussaleh, "APLIKASI DATABASE MASJID BERBASIS WEB GIS," no. January 2015, 2017.

[4] W. Bekasi and Y. D. Triyanti, "Aplikasi android untuk pencarian lokasi tempat ibadah di wilayah bekasi," vol. 8, no. Kommit, pp. 446-452, 2014.

[5] G. W. Sasmito, "Penerapan Metode Waterfall Pada Desain Sistem Informasi Geografis Industri Kabupaten Tegal,” vol. 2, no. 1, pp. 6-12, 2017. 